\title{
Amperometric Glucose Biosensor Utilizing Zinc Oxide-chitosan- glucose Oxidase Hybrid Composite Films on Electrodeposited Pt-Fe(III)
}

\author{
Eun-Sook PAIK, ${ }^{*}$ Yang-Rae KIM, ${ }^{* * \dagger}$ and Hun-Gi Hong ${ }^{* \dagger}$ \\ *Department of Chemistry Education, Seoul National University, Seoul 08826, Republic of Korea \\ **Department of Chemistry, Kwangwoon University, Seoul 01897, Republic of Korea
}

\begin{abstract}
We developed an amperometric glucose biosensor based on glucose oxidase (GOx) embedded in zinc oxide ( $\mathrm{ZnO}$ )chitosan (CS) hybrid composite films on electrodeposited Pt-Fe(III). This sensor exhibited a fast amperometric response (less than $10 \mathrm{~s}$ ) to glucose, linearity from $10 \mu \mathrm{M}$ to $11.0 \mathrm{mM}$ of glucose with a detection limit of $1.0 \mu \mathrm{M}(S / N=3)$ and sensitivity of $30.70 \mu \mathrm{A} \mathrm{mM} \mathrm{m}^{-1} \mathrm{~cm}^{-2}$. An apparent Michaelis-Menten constant of $5.19 \mathrm{mM}$ indicated high affinity between glucose and GOx immobilized in the ZnO-CS films. The effect of interferences such as uric acid, ascorbic acid, and acetaminophen on the performance of this sensor was negligible. In addition, this sensor retained $87 \%$ of its initial performance after two weeks of storage at $4^{\circ} \mathrm{C}$, indicating that the hybrid composite films allowed successful immobilization of GOx with its high enzymatic activity.
\end{abstract}

Keywords Glucose biosensor, glucose oxidase, chitosan, zinc oxide, composite film

(Received February 3, 2018; Accepted July 4, 2018; Published November 10, 2018)

\section{Introduction}

Enzyme biosensors are of great importance in a wide range of research fields, such as biological, clinical, environmental, and the food industry. ${ }^{1-3}$ Glucose sensors based on glucose oxidase (GOx) are a popular enzyme biosensor and have been important tools in clinical analysis for diagnosis of diabetes. ${ }^{4,5}$ Performance of such enzyme biosensors usually depends on the structure of the matrix for enzyme immobilization because it has significant effects on the activity of the enzymes embedded in the matrix.

Recently, a wide variety of inorganic and organic materials have been proposed as promising matrix, allowing for excellent biocompatibility, large surface area, fast charge transfer, and easy preparation. ${ }^{1,6-8}$ In particular, one inorganic material, zinc oxide $(\mathrm{ZnO})$, has attracted much attention for the preparation of enzyme biosensors due to its unique properties of low toxicity, chemical stability, and high electron communication. ${ }^{9-11}$ In addition, it is well known that organic layers such as chitosan (CS) and Nafion enable the formation of biocompatible films with long-term stability. ${ }^{12-14}$ As a result, inorganic-organic hybrid composite films have recently emerged to combine the advantages of each component in the matrix and improve the performance of enzyme biosensors. ${ }^{15-18}$

In this paper, we present an amperometric glucose biosensor based on GOx embedded in the ZnO-CS hybrid composite films on electrodeposited Pt-Fe(III). The surface morphology of these films was monitored by field emission-scanning electron microscope (FE-SEM) and their electrochemical behavior was

$\dagger$ To whom correspondence should be addressed.

E-mail: yrkim@kw.ac.kr (Y.-R. K.); hghong@ snu.ac.kr (H.-G. H.) investigated using cyclic voltammetry (CV) and electrochemical impedance spectroscopy (EIS). The applied potential and the value of $\mathrm{pH}$ were optimized to get the best performance of this glucose sensor. Finally, the limit of detection, MichaelisMenten constant, interference effect, reproducibility, and stability of this glucose sensor were intensively studied and compared to other glucose sensors.

\section{Experimental}

\section{Reagents and chemicals}

CS (85\% deacetylation), Nafion (5wt\%), zinc nitrate hexahydrate $(98 \%)$, GOx (from aspergillus niger, type II, enzyme commission number 1.1.3.4), D-(+)-glucose, hexamethylene tetramine (HMTA), trisodium citrate, acetic acid, phosphate buffered saline (PBS), and sodium acetate were purchased from Sigma-Aldrich (MO, USA). To prepare aqueous solutions, $18.0 \mathrm{M} \Omega \mathrm{cm}$ deionized water (Nano pure system, Barnsted) was used.

\section{Synthesis of porous $\mathrm{ZnO}$ microspheres}

Porous nanosheet-based $\mathrm{ZnO}$ microspheres were synthesized according to a previous report. ${ }^{10}$ Briefly, a homogeneous aqueous solution containing $50 \mathrm{mM}$ zinc nitrate, $50 \mathrm{mM}$ HMTA, and $5 \mathrm{mM}$ trisodium citrate was prepared by continuous stirring for $5 \mathrm{~h}$. The transparent mixture was heated at $95^{\circ} \mathrm{C}$ for $35 \mathrm{~min}$ and cooled to room temperature and finally, precipitates were formed. They were filtered and washed several times with deionized water and ethanol, and then dried in an oven at $65^{\circ} \mathrm{C}$. Finally, they were annealed at $300^{\circ} \mathrm{C}$ in air for $1 \mathrm{~h}$ to obtain the porous $\mathrm{ZnO}$ microspheres. 


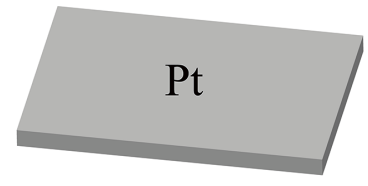

Pt-Fe(III) electrodeposition
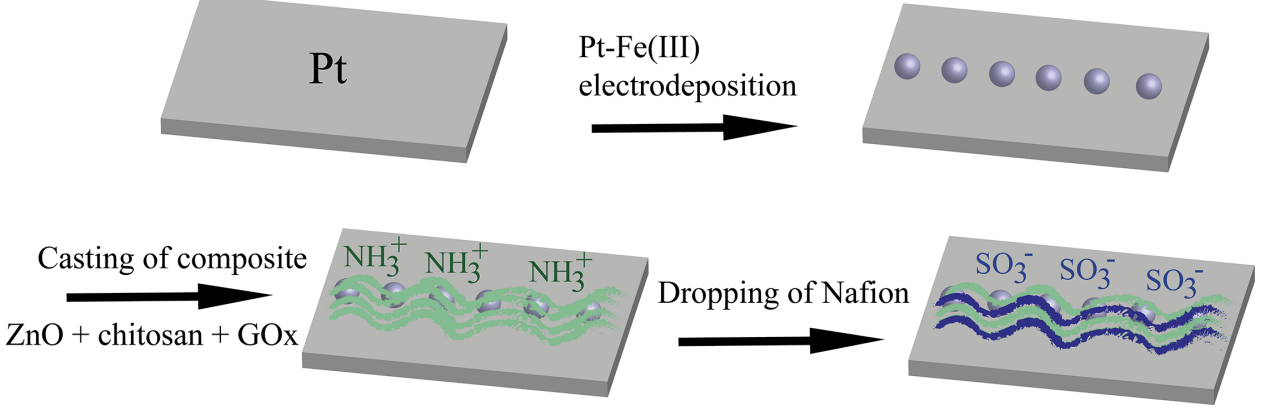

Fig. 1 Schematic illustration of the preparation process of a Nafion/ZnO-CS-GOx/Pt-Fe(III)/Pt electrode.

\section{Electrochemical measurements}

All electrochemical measurements were carried out using a conventional three-electrode system with an electrochemical analyzer (Models 440A or 760B, CH Instruments, USA). A Pt wire and an $\mathrm{Ag} / \mathrm{AgCl}$ wire $(3 \mathrm{M} \mathrm{KCl})$ were used as a counter and a reference electrode, respectively. Prior to amperometric measurements, the working electrode was equilibrated in stirred $0.10 \mathrm{M}$ PBS buffer ( $\mathrm{pH}$ 7.0) for at least $5 \mathrm{~min}$. The measurements were carried out at ambient temperature in $\mathrm{N}_{2}$-saturated buffer solution. EIS experiments were performed in $0.1 \mathrm{M} \mathrm{KCl}$ solution containing $5.0 \mathrm{mM}$ of $\left[\mathrm{Fe}(\mathrm{CN})_{6}\right]^{3-14-}(1: 1$ mixture $)$ as redox probes in the frequency range between $1.0 \times 10^{-1}$ and $1.0 \times 10^{5} \mathrm{~Hz}$ at the equilibrium potential. The EIS data were fitted to an appropriate equivalent circuit using ZsimpWin 3.0 software (Echem software, USA). FE-SEM images were obtained using a Hitachi S-4800 (Hitachi, Japan) at an accelerating voltage of $15 \mathrm{kV}$.

Preparation of glucose biosensors based on hybrid composite films

A Pt electrode ( $2 \mathrm{~mm}$ in diameter, $\mathrm{CH}$ Instruments, USA) was polished with $1.0,0.3$, and $0.05 \mu \mathrm{m}$ alumina slurry, respectively. It was rinsed thoroughly with deionized water and then sonicated in ethanol and deionized water for $10 \mathrm{~min}$, respectively, and finally dried under a stream of $\mathrm{N}_{2}$.

For electrodeposited Pt-Fe(III) particles, the Pt electrode was scanned between +0.7 and $-0.8 \mathrm{~V}$ at a scan rate of $50 \mathrm{mV} \mathrm{s}^{-1}$ for 50 cycles using $\mathrm{CV}$ in $0.1 \mathrm{M} \mathrm{KCl}$ solution containing $0.6 \mathrm{mM}$ $\mathrm{H}_{2} \mathrm{PtCl}_{6}$ and $0.4 \mathrm{mM} \mathrm{FeCl} 3$ according to previously reported procedures. ${ }^{19}$ The resulting electrode was rinsed with copious deionized water and denoted as $\mathrm{Pt}-\mathrm{Fe}(\mathrm{III}) / \mathrm{Pt}$.

GOx was then immobilized with $\mathrm{ZnO}$ and $\mathrm{CS}$ on the $\mathrm{Pt}-\mathrm{Fe}(\mathrm{III}) / \mathrm{Pt}$ as follows. Briefly, $25 \mathrm{mg}$ of CS was dissolved in $5 \mathrm{~mL}$ of $50 \mathrm{mM}$ acetate buffer solution and the $\mathrm{pH}$ value was adjusted to $\mathrm{pH} 7.0$ by adding $\mathrm{NaOH}$ solution. Then, $5 \mathrm{mg} \mathrm{mL}^{-1}$ of $\mathrm{ZnO}$ suspension in $0.1 \mathrm{M}$ PBS ( $\mathrm{pH} 7.0$ ) was mixed with the clear CS solution by stirring for $30 \mathrm{~min}$ and successively sonicated for $2 \mathrm{~h}$. Then, $200 \mu \mathrm{L}$ of $30 \mathrm{mg} \mathrm{mL}^{-1} \mathrm{GOx}$ in $0.1 \mathrm{M}$ PBS (pH 7.0) was mixed with $200 \mu \mathrm{L}$ of $\mathrm{ZnO}-\mathrm{CS}$ mixture solution. Next, $10 \mu \mathrm{L}$ of the $\mathrm{ZnO}-\mathrm{CS}-\mathrm{GOx}$ composite solution was cast onto the surface of $\mathrm{Pt}-\mathrm{Fe}(\mathrm{III}) / \mathrm{Pt}$ and allowed to dry at $4^{\circ} \mathrm{C}$. Finally, $10 \mu \mathrm{L}$ of $1 \%(\mathrm{v} / \mathrm{v})$ Nafion was cast again on the modified electrode surface. The obtained electrode (denoted as Nafion/ZnO-CS-GOx/Pt-Fe(III)/Pt) was stored at $4^{\circ} \mathrm{C}$. For comparison, Nafion/GOx/Pt and Nafion/CS-GOx/Pt-Fe(III)/Pt electrodes were also prepared using the same procedure described above. It should be noted that the quantity of GOx load onto the modified electrodes was consistent.

\section{Results and Discussion}

\section{Morphologies of the modified electrodes}

The details of the preparation process of the glucose biosensor are illustrated in Fig. 1. To investigate the microstructure of the electrodes as modification proceeds, the morphologies of the modified electrodes were characterized using FE-SEM. First, $\mathrm{Pt}-\mathrm{Fe}$ (III) particles were electrodeposited on a Pt electrode for efficient charge transfer between electrode and GOx. Figure 2(a) is a FE-SEM image of the electrodeposited Pt-Fe(III) particles, which are a tetragonal shape with sizes in the range of $1-4 \mu \mathrm{m}$. GOx was mixed with $\mathrm{ZnO}$ and $\mathrm{CS}$ solutions to form the composite films with enhanced biocompatibility and cast on the $\mathrm{Pt}-\mathrm{Fe}(\mathrm{III}) / \mathrm{Pt}$ electrode. Figure 2(b) shows FE-SEM images of the as-prepared $\mathrm{ZnO}$ microspheres, which have diameters in the range of $1-3 \mu \mathrm{m}$. The higher magnification image (inset in Fig. 2(b)) represents that the microspheres have a flower-like structure consisting of numerous interconnected nanosheets with the thickness in the range of $9-15 \mathrm{~nm}$. The flower-like nanostructure of $\mathrm{ZnO}$ creates many nanosized cavities, which provide a large surface area for immobilization of GOx. When the $\mathrm{ZnO}$ microspheres were incorporated with $\mathrm{CS}$ on the Pt$\mathrm{Fe}(\mathrm{III}) / \mathrm{Pt}$ electrode, the resulting films displayed threedimensional cubic porous morphology due to the homogenous dispersion of $\mathrm{ZnO}$ microspheres in the CS film (Fig. 2(c)). When GOx was embedded in the $\mathrm{ZnO}-\mathrm{CS}$ films, the cubic porous morphology of the ZnO-CS layer changed more regularly, which indicates effective loading of GOx inside the films (Fig. 2(d)). The particles tend to aggregate in the absence of GOx, as shown in Fig. 2(c). After incorporation of GOx, the particle size is smaller than before, indicating that GOx-ZnO-Cs is more homogenously dispersed in solution and the hybrid composite films are uniformly coated at the electrode surface. Finally, Nafion was coated on top of the ZnO-CS-GOx composite films for long-term stability and selectivity.

\section{Electrochemical impedance characterization of the modified electrodes}

The electrochemical behavior of the modified electrodes was characterized using CV and EIS during the stepwise-assembling process. Figure 3 shows Nyquist plots of the modified electrodes in $0.1 \mathrm{M} \mathrm{KCl}$ solution containing $5.0 \mathrm{mM}$ of $\left[\mathrm{Fe}(\mathrm{CN})_{6}\right]^{3-14-}(1: 1$ mixture) as redox probes at the equilibrium potential. Complex impedance is estimated according to the following Eq. (1).

$$
Z^{*}(w)=Z^{\prime}(w)+j Z^{\prime \prime}(w), \quad w=2 \pi f
$$




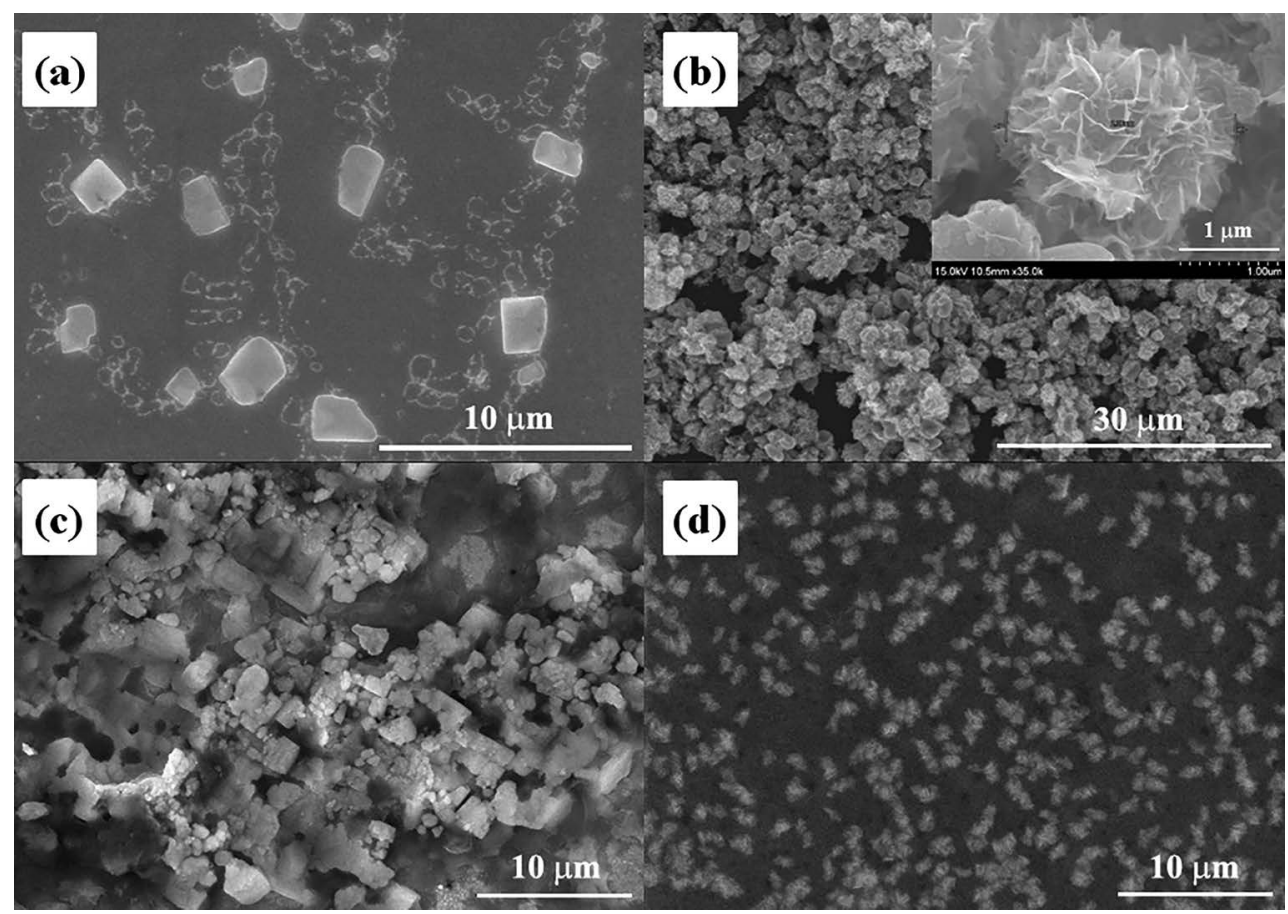

Fig. 2 FE-SEM images of (a) a Pt-Fe(III)/Pt electrode, (b) as-prepared $\mathrm{ZnO}$ microspheres (inset: higher magnification), (c) a ZnO-CS/Pt-Fe(III)/Pt electrode, and (d) a ZnO-CS-GOx/Pt-Fe(III)/Pt electrode.

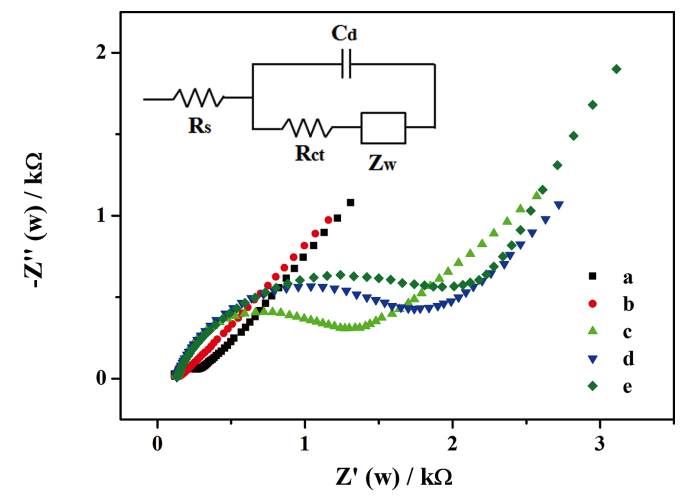

Fig. 3 Nyquist plots of (a) a bare Pt electrode, (b) a Pt-Fe(III)/Pt electrode, (c) a ZnO-CS/Pt-Fe(III)/Pt electrode, (d) a ZnO-CS-GOx/ $\mathrm{Pt}-\mathrm{Fe}(\mathrm{III}) / \mathrm{Pt}$ electrode, and (e) a Nafion/ZnO-CS-GOx/Pt-Fe(III)/Pt electrode obtained in $5.0 \mathrm{mM} \mathrm{K}_{3} \mathrm{Fe}(\mathrm{CN})_{6} / \mathrm{K}_{4} \mathrm{Fe}(\mathrm{CN})_{6}(1: 1)$ containing $0.1 \mathrm{M} \mathrm{KCl}$.

Where $w$ is the angular frequency and $f$ is frequency. The inset of Fig. 3 shows the Randle's equivalent circuit model used to fit the impedance spectra. It consists of double layer capacitance $\left(C_{\mathrm{d}}\right)$, charge-transfer resistance $\left(R_{\mathrm{ct}}\right)$, solution resistance $\left(R_{\mathrm{s}}\right)$ and Warburg impedance $\left(Z_{\mathrm{w}}\right)$.

The semicircle diameter of the impedance spectra represents the charge-transfer resistance, $R_{\mathrm{ct}}$, which is affected by the charge transfer kinetics of redox probes at the electrode surface. The Pt-Fe(III)/Pt electrode shows a lower $R_{\mathrm{ct}}(35.2 \Omega)$ than that of the bare Pt electrode (160.8 $\Omega$ ), which indicates that the electrodeposited Pt-Fe(III) particles improve the charge transfer process (Fig. 3, a and b). After casting of the mixture solution of $\mathrm{ZnO}-\mathrm{CS}$ on the Pt-Fe(III)/Pt electrode (i.e. the $\mathrm{ZnO}-\mathrm{CS} / \mathrm{Pt}-$ $\mathrm{Fe}(\mathrm{III}) / \mathrm{Pt}$ electrode), the value of $R_{\mathrm{ct}}$ is significantly increased to
$1151.0 \Omega$ due to formation of the $\mathrm{ZnO}-\mathrm{CS}$ films with their lower conductivity and hindrance effect on the charge transfer of redox probes (Fig. 3, c). The value of $R_{\mathrm{ct}}$ on the $\mathrm{ZnO}-\mathrm{CS}-\mathrm{GOx} /$ $\mathrm{Pt}-\mathrm{Fe}(\mathrm{III}) / \mathrm{Pt}$ electrode is also increased to $1604.0 \Omega$ compared to that $(1151.0 \Omega$ ) on the $\mathrm{ZnO}-\mathrm{CS} / \mathrm{Pt}-\mathrm{Fe}(\mathrm{III}) / \mathrm{Pt}$ electrode, indicating that GOx has a similar electrical property to the $\mathrm{ZnO}$ CS films (Fig. 3, d). Coating of Nafion on the top of ZnO-CSGOx films causes a slight increase in the value of $R_{\mathrm{ct}}(1718.0 \Omega)$ (Fig. 3, e), indicating that Nafion hinders the charge transfer process of the redox probes due to electrostatic repulsion between Nafion and redox probes.

\section{Cyclic voltammetric response of the GOx-immobilized electrodes} to glucose

Figure 4 shows cyclic voltammograms obtained on the modified electrodes in 0.1 M PBS ( $\mathrm{pH} 7.0)$ solution in the absence or presence of $5.0 \mathrm{mM}$ glucose at a scan rate of $50 \mathrm{mV} \mathrm{s}^{-1}$. First, a cyclic voltammogram of the Nafion/ZnOCS-GOx/Pt-Fe(III)/Pt electrode was obtained in the absence of glucose, which displays only a low background current (Fig. 4, a). When $5.0 \mathrm{mM}$ glucose was added into the PBS solution, an anodic current peak at around $0.6 \mathrm{~V}$ was clearly observed (Fig. 4, d). The anodic current is attributed to the redox behavior of Pt-Fe(III) particles as a mediator for catalytic oxidation of glucose through GOx and is noticeably higher than those on the Nafion/GOx/Pt and Nafion/CS-GOx/Pt-Fe(III)/Pt electrodes (Fig. 4, b and c). It is assumed that surface coverage of Pt-Fe(III) particles was high for oxidation of glucose because they were formed through electrodeposition processes at enough overpotential, which is proved by a SEM image (Fig. 2(a)). Furthermore, it is expected that fast electron transfer through Pt-Fe(III) particles, which is shown by EIS data in Fig. 3, b, enables outer electron transfer processes between Pt-Fe(III) and GOx even if there is a long distance. In addition, the value of an onset potential $(0.07 \mathrm{~V})$ on the Nafion/ZnO-CS-GOx/ 


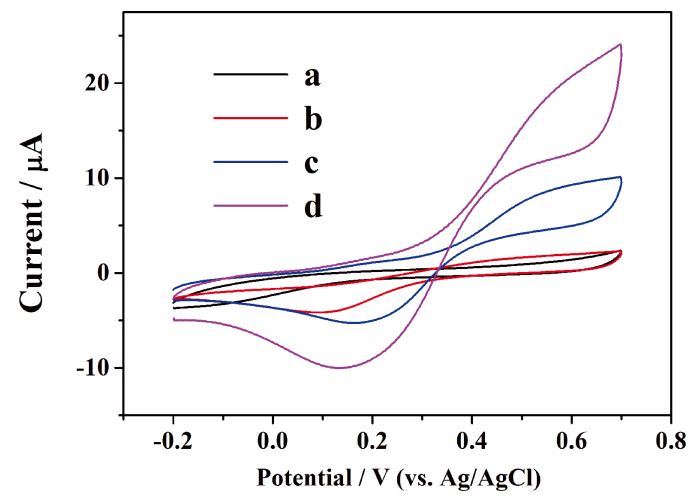

Fig. 4 Cyclic voltammograms obtained on the modified electrodes in the absence or presence of glucose. (a) Nafion/ZnO-CS-GOx/Pt$\mathrm{Fe}(\mathrm{III}) / \mathrm{Pt}$ electrode in glucose-free 0.1 M PBS solution ( $\mathrm{pH} 7.0$ ), (b) Nafion/GOx/Pt electrode, (c) Nafion/CS-GOx/Pt-Fe(III)/Pt electrode, and (d) Nafion/ZnO-CS-GOx/Pt-Fe(III)/Pt electrode in $0.1 \mathrm{M}$ PBS solution ( $\mathrm{pH} 7.0$ ) containing $5.0 \mathrm{mM}$ glucose. Scan rate: $50 \mathrm{mV} \mathrm{s}^{-1}$.

(a)

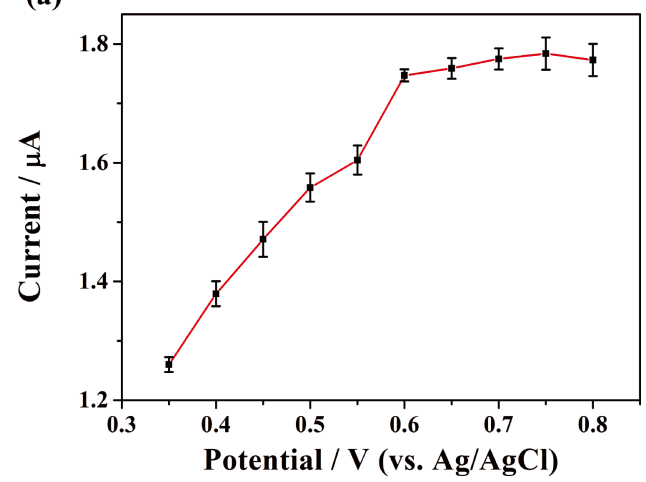

(b)

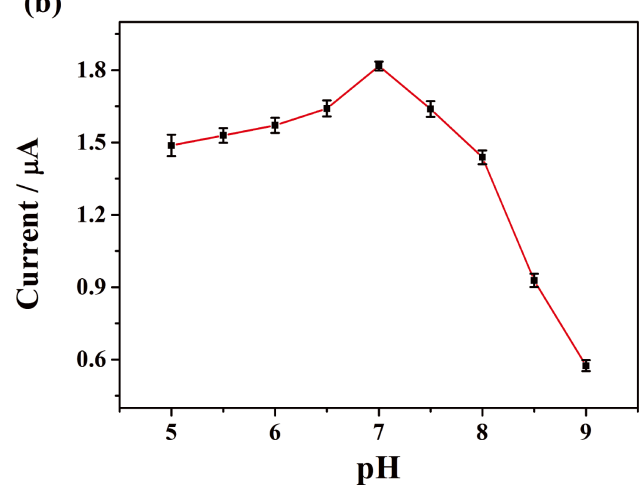

Fig. 5 Effects of (a) applied potential and (b) $\mathrm{pH}$ on steady-state response current of glucose on a Nafion/ZnO-CS-GOx/Pt-Fe(III)/Pt electrode in $0.1 \mathrm{M}$ PBS solution (pH 7.0) containing $5.0 \mathrm{mM}$ glucose. Error bars show standard deviations for three independent electrodes.

$\mathrm{Pt}-\mathrm{Fe}(\mathrm{III}) / \mathrm{Pt}$ electrode is more negative than those on the Nafion/ GOx/Pt $(0.22 \mathrm{~V})$ and Nafion/CS-GOx/Pt-Fe(III)/Pt $(0.085 \mathrm{~V})$ electrodes. These results indicate that the hybrid composite films consisting of $\mathrm{ZnO}, \mathrm{CS}$, and $\mathrm{Pt}-\mathrm{Fe}$ (III) particles improve electrocatalytic oxidation of glucose considerably, which can be attributed to the increased surface area and faster electron transfer rate.
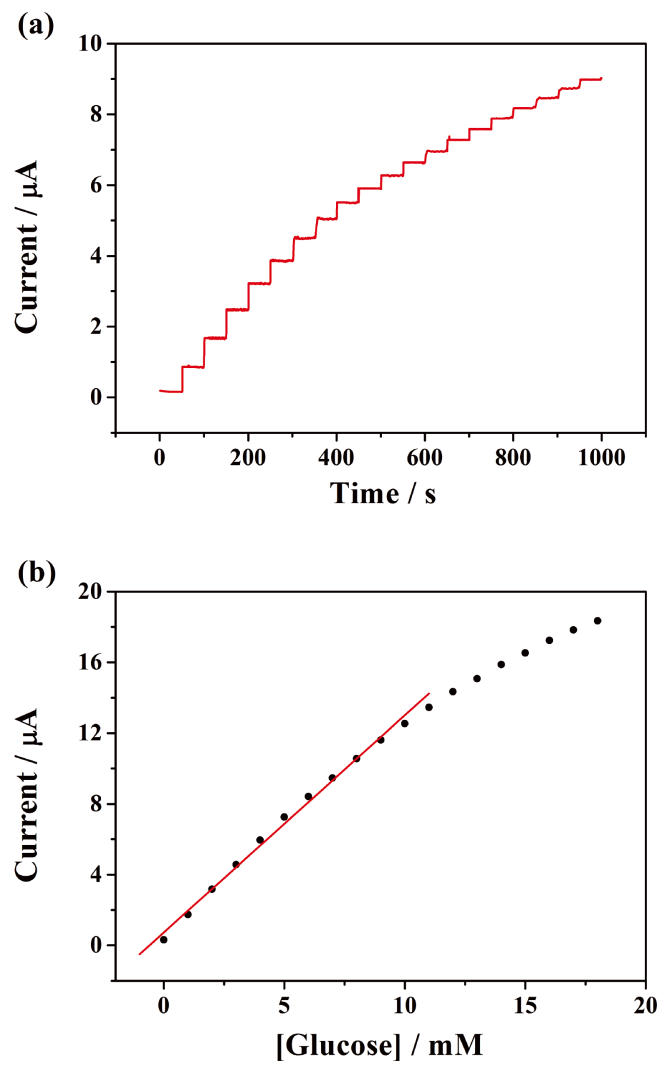

(c)

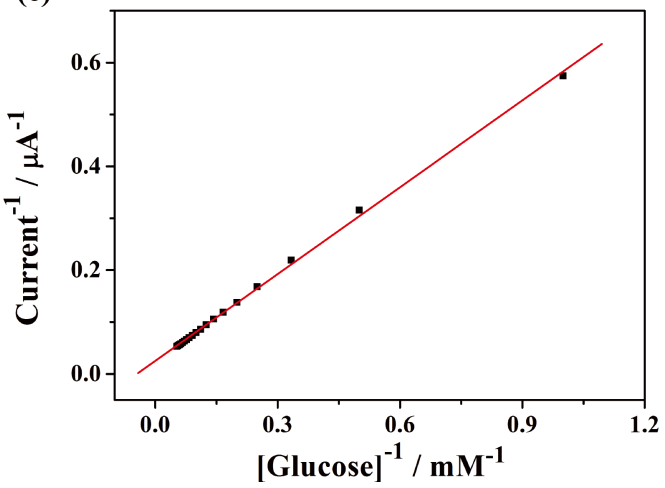

Fig. 6 (a) Amperometric responses of a Nafion/ZnO-CS-GOx/Pt$\mathrm{Fe}(\mathrm{III}) / \mathrm{Pt}$ electrode at an applied potential of $600 \mathrm{mV}$ by successive addition of glucose $(1.0 \mathrm{mM} / \mathrm{step})$ in $0.1 \mathrm{M}$ PBS ( $\mathrm{pH} 7.0)$ under continuous stirring. (b) Michaelis-Menten and (c) Lineweaver-Burk plots. The straight lines are linear fits to the plots.

Optimization of measurement variables for amperometric determination of glucose

The measurement variables such as applied potential and $\mathrm{pH}$ value of supporting electrolyte were optimized; these variables affect the performance of the glucose biosensor. First, influence of applied potential values on the amperometric determination of glucose $(5.0 \mathrm{mM})$ was explored on the Nafion/ZnO-CS-GOx/ $\mathrm{Pt}-\mathrm{Fe}(\mathrm{III}) / \mathrm{Pt}$ electrode. Figure 5(a) shows that the oxidation current grows rapidly with an increase in potential from $0.35 \mathrm{~V}$ and reaches a plateau at $0.6 \mathrm{~V}$. To avoid unnecessary interferences at high overpotentials, a potential of $0.6 \mathrm{~V}$ was selected for subsequent amperometric measurements.

The effect of $\mathrm{pH}$ values in the range of 5.0-9.0 on the detection of glucose $(5.0 \mathrm{mM})$ at $0.6 \mathrm{~V}$ was also investigated. 
Table 1 Comparison of analytical performance of the proposed glucose biosensor with those of biosensors reported earlier

\begin{tabular}{|c|c|c|c|c|c|}
\hline & $\begin{array}{c}\text { Sensitivity/ } \\
\mu \mathrm{A} \mathrm{mM} \mathrm{m}^{-1} \mathrm{~cm}^{-2}\end{array}$ & $\begin{array}{c}\text { Detection limit/ } \\
\mu \mathrm{M}\end{array}$ & $\begin{array}{c}\text { Linear range/ } \\
\mathrm{mM}\end{array}$ & $\begin{array}{c}K_{\mathrm{M}}^{\mathrm{app} /} \\
\mathrm{mM}\end{array}$ & Reference \\
\hline Nafion/ZnO-CS-GOx/Pt-Fe(III) & 30.70 & 1.0 & $0.010-11.0$ & 5.19 & This work \\
\hline Nafion/ZnO hollow nanospheres/GOx & 65.82 & 1.0 & $0.005-13.15$ & N.A. ${ }^{a}$ & 9 \\
\hline Au nanoparticles/GOx-horseradish peroxidase/thiol & 41.78 & 5.4 & $0.0165-10.0$ & N.A. ${ }^{a}$ & 21 \\
\hline Nafion/GOx/poly(taurine) & 26.58 & 64 & $0.9-15$ & N.A. ${ }^{a}$ & 22 \\
\hline Nafion/GOx/carbon Vulcan & 125 & 300 & $0.3-45$ & N.A. ${ }^{a}$ & 23 \\
\hline GOx/sol-gel/CS & 0.274 & 10 & $2-14$ & 21 & 24 \\
\hline Nafion/GOx/SWCNHs & 1.06 & 6 & $0-6$ & 8.5 & 25 \\
\hline Au nanoparticles/MWNT/GOx & 7.3 & 128 & $0-9$ & 10.6 & 26 \\
\hline
\end{tabular}

a. N.A is not applicable.

Figure 5(b) shows that the oxidation current reaches its maximum value at $\mathrm{pH} 7.0$, which is in good agreement with previous reports for immobilization of GOx in the CS films. . $^{15,16,20}$ This result can be attributed to degradation of GOx and CS in acidic and basic media. ${ }^{15}$ The $\mathrm{pH}$ value of 7.0 was thus chosen for all electrochemical experiments.

Amperometric performance of the prepared glucose biosensor

The dynamic amperometric response of the Nafion/ZnO-CS$\mathrm{GOx} / \mathrm{Pt}-\mathrm{Fe}(\mathrm{III}) / \mathrm{Pt}$ electrode was investigated through successive addition of glucose (1.0 mM per each injection step) in $0.1 \mathrm{M}$ PBS solution ( $\mathrm{pH} 7.0$ ) at $0.6 \mathrm{~V}$ under continuous stirring. A rapid and sensitive response was observed upon the addition of glucose as shown in Fig. 6(a). The current reaches the steady-state with about 95\% magnitude in less than $10 \mathrm{~s}$, indicating fast electron transfer between GOx and electrode. The current is increased linearly to the concentration of glucose in the range of $10 \mu \mathrm{M}-11.0 \mathrm{mM}$, and the linear regression equation is $i / \mu \mathrm{A}=0.73+1.23\left[\right.$ Glucose] $/ \mathrm{mM}^{-1}, \quad R^{2}=0.997$ (Fig. 6(b)). In addition, the sensitivity and the limit of detection are estimated to be $30.70 \mu \mathrm{A} \mathrm{mM}^{-1} \mathrm{~cm}^{-2}$ and $1.0 \mu \mathrm{M}(S / N=3)$, respectively.

The Michaelis-Menten constant $\left(K_{\mathrm{M}}{ }^{\text {app }}\right)$, which is a measure of the enzymatic activity, can be obtained from the following Lineweaver-Burk equation (Eq. (2)).

$$
1 / i=\left(K_{\mathrm{M}}^{\mathrm{app}} / i_{\max }\right)(1 / C)+1 / i_{\max }
$$

Where $i$ is the current, $i_{\max }$ is the maximum current, and $C$ is the concentration of glucose. From the curve $1 / i$ versus $1 / C$ based on the experimental data from Fig. 6(c), the value of $K_{\mathrm{M}}$ app is estimated to be $5.19 \mathrm{mM}$, which is smaller than those in previous reports as shown in Table $1 . .^{21-26}$ The smaller $K_{\mathrm{M}}{ }^{\text {app }}$ indicates high affinity between glucose and GOx immobilized in the $\mathrm{ZnO}-\mathrm{CS}$ films. Therefore, it is reasonable to evaluate that the proposed Nafion/ZnO-CS-GOx/Pt-Fe(III)/Pt electrode provides a superior microenvironment for retaining enzymatic activity of the embedded GOx.

The effect of electroactive interferences such as uric acid (UA), ascorbic acid (AA), and acetaminophen (AAP) on the amperometric determination of glucose was studied by successive addition of glucose $(1.0 \mathrm{mM})$ and interferences $(0.1 \mathrm{mM})$ in $0.1 \mathrm{M}$ PBS solution $(\mathrm{pH} 7.0)$. These interferences are often found in physiological samples and cause problems for accurate determination of glucose. ${ }^{27}$ Figure 7 shows that the amperometric responses of the interferences were negligible, which indicates the proposed glucose biosensor has good antiinterference ability. It is assumed that Nafion contributes to the selective detection of glucose through electrostatic repulsion

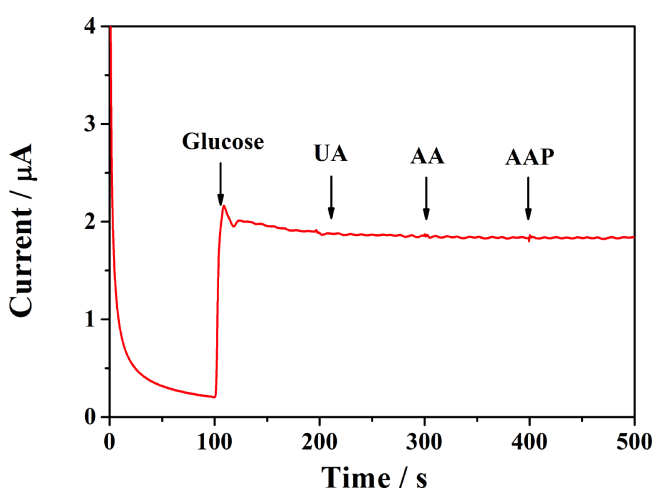

Fig. 7 Amperometric responses of a Nafion/ZnO-CS-GOx/Pt$\mathrm{Fe}(\mathrm{III}) / \mathrm{Pt}$ electrode by successive addition of glucose $(1.0 \mathrm{mM})$ and interference species (0.1 mM each) in 0.1 M PBS solution ( $\mathrm{pH} 7.0)$.

between Nafion and interferences.

The reproducibility and stability of the electrode were also investigated. The value of relative standard deviation (RSD) to $1.0 \mathrm{mM}$ of glucose was $2.8 \%$ for ten successive measurements. For seven independent electrodes prepared identically, the value of RSD for the amperometric determination of $1.0 \mathrm{mM}$ glucose was $4.1 \%$. The stability was investigated by measuring the performance of the electrode after storing it at $4{ }^{\circ} \mathrm{C}$ for two weeks. The current response remained at $87 \%$ of its initial value after two weeks. Table 1 shows the overall performance of this glucose biosensor with those of the biosensors reported earlier. It is clearly shown that the proposed glucose biosensor displays superior performance including high sensitivity, fast response time, and excellent stability for amperometric determination of glucose, which is better or at least comparable to those of the previously reported glucose biosensors.

\section{Conclusions}

In this work, we report a glucose biosensor utilizing $\mathrm{ZnO}-\mathrm{CS}$ GOx composite film on Pt-Fe(III) electrodeposited Pt electrode. This composite matrix combines the merits of two materials, $\mathrm{ZnO}$ and $\mathrm{CS}$, and provides a suitable microenvironment for GOx enzyme immobilization. Therefore, the proposed glucose biosensor exhibits good analytical performance, including broad linear range, high sensitivity, fast and stable response to glucose as well as anti-interference ability to possible interference species. The results indicate that the proposed $\mathrm{ZnO}-\mathrm{CS}-\mathrm{Nafion}$ composite film is an attractive matrix for the immobilization of 
GOx to fabricate biosensors. The adapted methodology in the present study can be extended for the development of a variety of other biosensors.

\section{Acknowledgements}

This work was supported by the National Research Foundation of Korea (2016R1C1B2011912) for Y.-R. K.

\section{References}

1. D. van der Voort, C. A. McNeil, R. Renneberg, J. Korf, W. T. Hermens, and J. F. C. Glatz, Sens. Actuators, B, 2005, 105, 50.

2. S. V. Dzyadevych, A. P. Soldatkin, Y. I. Korpan, V. N. Arkhypova, A. V. El'skaya, J.-M. Chovelon, C. Martelet, and N. Jaffrezic-Renault, Anal. Bioanal. Chem., 2003, 377, 496

3. S. K. Arya, M. Datta, and B. D. Malhotra, Biosens. Bioelectron., 2008, 23, 1083.

4. A. Heller and B. Feldman, Chem. Rev., 2008, 108, 2482.

5. J. Wang, Chem. Rev., 2008, 108, 814.

6. A. Umar, M. M. Rahman, S. H. Kim, and Y. B. Hahn, $J$. Nanosci. Nanotechnol., 2008, 8, 3216.

7. J. X. Wang, X. W. Sun, A. Wei, Y. Lei, X. P. Cai, C. M. Li, and Z. L. Dong, Appl. Phys. Lett., 2006, 88, 233106.

8. E. Topoglidis, A. E. G. Cass, B. O'Regan, and J. R. Durrant, J. Electroanal. Chem., 2001, 517, 20.

9. B. Fang, C. Zhang, G. Wang, M. Wang, and Y. Ji, Sens. Actuators, B, 2011, 155, 304.

10. X. Lu, H. Zhang, Y. Ni, Q. Zhang, and J. Chen, Biosens. Bioelectron., 2008, 24, 93.

11. Z. Dai, G. Shao, J. Hong, J. Bao, and J. Shen, Biosens.
Bioelectron., 2009, 24, 1286.

12. M. Yang, Y. Yang, B. Liu, G. Shen, and R. Yu, Sens. Actuators, B, 2004, 101, 269.

13. C. Xian, L. Chengchao, L. Yanli, D. Zhifeng, X. Shoujiang, L. Limiao, Z. Ming, and W. Taihong, Talanta, 2008, 77, 37.

14. W. Mattanavee, O. Suwantong, S. Puthong, T. Bunaprasert, V. P. Hoven, and P. Supaphol, ACS Appl. Mater. Interfaces, 2009, 1, 1076.

15. J.-D. Qiu, R. Wang, R.-P. Liang, and X.-H. Xia, Biosens. Bioelectron., 2009, 24, 2920.

16. Y. Yang, H. Yang, M. Yang, Y. Liu, G. Shen, and R. Yu, Anal. Chim. Acta, 2004, 525, 213.

17. Z. Wang, Y. Yang, J. Li, J. Gong, G. Shen, and R. Yu, Talanta, 2006, 69, 686.

18. R. Khan, A. Kaushik, P. R. Solanki, A. A. Ansari, M. K. Pandey, and B. D. Malhotra, Anal. Chim. Acta, 2008, 616, 207.

19. S. Wang, Y. Yin, and X. Lin, Electrochem. Commun., 2004, $6,259$.

20. Y. Wang, J. Zhu, R. Zhu, Z. Zhu, Z. Lai, and Z. Chen, Meas. Sci. Technol., 2003, 14, 831.

21. C. Gong, J. Chen, Y. Song, M. Sun, Y. Song, Q. Guo, and L. Wang, Anal. Methods, 2016, 8, 1513.

22. R. Madhu, B. Devadas, S. M. Chen, and M. Rajkumar, Anal. Methods, 2014, 6, 9053.

23. M. Ammam and E. B. Easton, Sens. Actuators, B, 2011, 155,340 .

24. X. Chen, J. Jia, and S. Dong, Electroanalysis, 2003, 15, 608.

25. X. Liu, L. Shi, W. Liu, H. Li, and G. Xu, Biosens. Bioelectron., 2008, 23, 1887.

26. Y. Liu, S. Wu, H. Ju, and L. Xu, Electroanalysis, 2007, 19 , 986.

27. X. Kang, Z. Mai, X. Zou, P. Cai, and J. Mo, Anal. Biochem., 2007, 369, 71 